\title{
Ingestão, digestibilidade das rações e parâmetros sangüíneos em cabras Saanen durante o pré-parto recebendo rações com diferentes níveis de energia ${ }^{1}$
}

\author{
Maximiliane Alavarse Zambom ${ }^{2}$, Claudete Regina Alcalde ${ }^{3^{*}}$, Francisco de Assis Fonseca de \\ Macedo $^{3^{*}}$, Jocilaine Garcia ${ }^{2}$, Gentil Vanini de Moraes ${ }^{3}$, Marlene Leiko Doi Sakuno ${ }^{4}$, \\ Everton Luiz Borgh ${ }^{5}$
}

\footnotetext{
1 Parte da dissertação de Mestrado da primeira autora apresentada à UEM.

2 Programa de Pós-Graduação em Zootecnia da Universidade Estadual de Maringá - UEM. Bolsista CAPES.

${ }^{3}$ Departamento de Zootecnia da Universidade Estadual de Maringá - UEM. Av. Colombo 5790, CEP 87020-900, Maringá

${ }^{4}$ Departamento de Análises Clínicas da UEM, Maringá - PR.

${ }^{5}$ Graduação em Zootecnia. Bolsista de IC/CNPq.

* Pesquisador CNPq.
}

RESUMO - O objetivo neste trabalho foi avaliar a ingestão e a digestibilidade dos nutrientes das rações e os parâmetros sangüíneos de 20 cabras Saanen $(70,65 \pm 7,39 \mathrm{~kg})$ no período de 21 dias pré-parto, em condições de confinamento. Foram utilizados cinco níveis de energia 2,95;2,83;2,70; 2,58 e 2,46 Mcal de EM/kg de MS, com as respectivas relações volumoso:concentrado 40:60, 50:50, 60:40, 70:30 e 80:20. O delineamento utilizado foi o inteiramente casualizado, com quatro repetições por tratamento. Os níveis de energia não influenciaram o peso vivo e as ingestões de MS, MO, PB, CT, FDN e NDT. No entanto, verificou-se efeito linear positivo da energia da ração sobre a ingestão de EE. Os níveis energéticos da ração influenciaram a digestibilidade dos nutrientes, observando-se efeito linear positivo para MS, MO, EE, FDN, CT e EB, todavia, não houve efeito para PB. Não houve efeito dos tratamentos sobre os valores de colesterol e uréia, mas verificou-se efeito linear positivo do nível energético da ração sobre os níveis de triglicerídeos (mg/dL). O nível de energia de $2,95 \mathrm{Mcal} / \mathrm{kg}$ de MS da ração resultou em maior disponibilidade de nutrientes em cabras Saanen no período pré-parto

Palavras-chave: digestão, nível energético, período de transição, uréia sanguínea

\section{Intake, nutrient digestibility, and blood parameters on prepartum Saanen goats fed diets with different energy levels}

\begin{abstract}
The objective of this study was to evaluate nutrient intake, blood parameters and digestibility of nutrients on 20 feedlot Saanen goats $(70.65 \pm 7.39 \mathrm{~kg})$ at 21 days prepartum. Diets with the following energy levels and forage:concentrate ratios were fed: $2.95,2.83,2.70,2.58$, and 2.44 Mcal of ME/kg of DM and 40:60, 50:50, 60:40, 70:30, and 80:20, respectively. A completely randomized design with four replications per treatment was used. Animal body weight and blood samples were taken weekly. The different dietary energy levels did not affect body weight ( $\mathrm{kg}$ ) and intakes of DM, OM, CP, TC, NDF, and TDN. However, a significant linear effect was observed for intake of EE by increasing the dietary energy level. With the exception of CP, apparent digestibilities of DM, OM, EE, NDF, TC, and GE all increased linearly when the energy content of the diet increased from 2.44 to $2.95 \mathrm{Mcal}$ of ME/ $\mathrm{kg}$ of DM. No significant effects were observed for the blood concentrations of cholesterol and urea among treatments. Conversely, concentration of blood triglycerides accompanied the increment of energy in the diet and increased linearly. It can be concluded that the diet with $2.95 \mathrm{Mcal}$ of $\mathrm{ME} / \mathrm{kg}$ of DM resulted in greater nutrient availability than diets with lower energy content when fed to prepartum Saanen goats.
\end{abstract}

Key Words: digestion, energy level, transition period, blood urea

\section{Introdução}

Durante o período de transição, correspondente ao final da gestação e início da lactação (três semanas anteriores e três posteriores ao parto), ocorre redução na ingestão de MS, que pode atingir níveis em torno de 25 a $35 \%$ em vacas (Drackley, 1999). A maximização da ingestão durante este período é fundamental para aumentar o suprimento de energia e proteína, evitando a mobilização de tecidos corporais e minimizando a possibilidade da ocorrência de doenças metabólicas (Head \& Gulay, 2001).

As causas de deficiência de energia nos animais podem estar associadas à baixa ingestão e/ou qualidade dos alimentos, principalmente, o alto teor de fibra ou o baixo 
conteúdo de MS no alimento. Segundo o NRC (2001), o fornecimento de ração mais energética e com os mesmos ingredientes da ração de lactação durante três semanas préparto promove benefícios no período de lactação de vacas leiteiras.

Segundo Wittwer (2000a), a análise da concentração sangüínea de variáveis como $\beta$-hidroxibutirato $(\beta \mathrm{HB})$, uréia e colesterol são importantes fatores para avaliar o balanço energético de ruminantes.

Os corpos cetônicos, $\beta \mathrm{HB}$ e acetoacetato são fontes de energia na ausência de glicídeos e lipídeos nos ruminantes. $\mathrm{O}$ aumento dos corpos cetônicos no sangue pode ocasionar um estado de cetose no animal, que ocorre quando há déficit de energia, elevando o nível de ácidos graxos livres e colesterol no sangue (Wittwer, 2000b).

A via metabólica protéica é representada pela uréia, pois depende do aporte de proteínas degradáveis da ração. Entretanto, o valor energético da ração também tem efeito sobre a uréia, pois, se o consumo de energia é baixo, o metabolismo dos microrganismos ruminais é alterado, ocasionando aumento na concentração de uréia sangüínea (Contreras et al., 2000).

Sahlu et al. (1995) avaliaram os 90 dias finais de gestação de cabras Alpinas $(52,90 \mathrm{~kg})$ utilizando um fatorial $3 \times 3$, composto de três níveis de $\mathrm{PB}(8,5 ; 11,5$ e $14,5 \%)$ e três de EM $(1,80 ; 2,16$ e $2,53 \mathrm{Mcal} / \mathrm{kg}$ de MS $)$, e não verificaram diferenças para a ingestão de MS, o peso vivo e a concentração de uréia no sangue entre diferentes níveis de energia. Os teores de PB alteraram apenas a concentração de uréia sangüínea.

Arruda et al. (1996), em estudo com cabras mestiças (Alpina x Moxotó) aos 100 dias de gestação alimentadas com três diferentes dietas, verificaram que os animais que receberam suplementação energética e protéica durante o período final de gestação produziram mais leite na lactação subseqüente.

Rodrigues et al. (2001) avaliaram os últimos 30 dias de gestação de cabras Alpinas, divididas em três grupos, recebendo dietas com $13 \%$ de PB e 1,0; 1,4 ou $1,7 \mathrm{Mcal} \mathrm{EL} / \mathrm{kg}$ MS e constataram que a ingestão de MS foi maior para as dietas com maiores níveis energéticos e que a ingestão de FDN foi menor.

Beynen et al. (2000) estudaram a influência do nível de gordura na dieta $(2,6 ; 8,4$ ou $8,8 \%$ de EE) e no plasma por meio da análise das concentrações de colesterol e triglicerídeos em cabras Dutch White não-gestantes e não-lactantes $(58,8 \mathrm{~kg})$. Esses autores notaram que a utilização de altos níveis de óleo na dieta $( \pm 8,6 \%)$ elevou os níveis de colesterol $(156,89 \mathrm{mg} / \mathrm{dL})$ e triglicerídeos $(16,77 \mathrm{mg} / \mathrm{dL})$ no plasma.
Neste estudo, objetivou-se avaliar a ingestão e a digestibilidade das rações e dos nutrientes e os parâmetros sangüíneos de cabras Saanen durante o período pré-parto recebendo cinco níveis de energia nas rações.

\section{Material e Métodos}

O experimento foi realizado no período de junho e julho de 2002, no Setor de Caprinocultura da Fazenda Experimental de Iguatemi e no Laboratório de Análise de Alimentos e Nutrição Animal da Universidade Estadual de Maringá (UEM).

Foram utilizadas 20 cabras Saanen $(70,65 \pm 7,39 \mathrm{~kg})$ do $21^{\circ}$ dia antes do parto até a data do parto, alocadas nos tratamentos conforme o nível de produção de leite na lactação anterior, o peso vivo, a idade e a ordem de parto. As cabras foram mantidas em baias individuais com bebedouro e comedouro, onde receberam alimentação duas vezes ao dia, às 8 e 16h. Logo após a alimentação da manhã, os animais eram conduzidos a um solário.

Os tratamentos testados consistiram de três níveis de energia na ração $(2,95 ; 2,83 ; 2,70 ; 2,58$ e 2,46 Mcal de EM/kg de MS), correspondendo às relações volumoso:concentrado 40:60, 50:50, 60:40, 70:30 e 80:20. O balanceamento das rações foi feito com base nas exigências de energia e proteína metabolizáveis descritos pela AFRC (1993) e nas exigências de minerais propostas pelo NRC (1981) para cabras Saanen de $60 \mathrm{~kg}$ de PV com produção de 3,0 kg de leite/dia. Para aumentar o teor de EM das rações (Tabela 1), utilizou-se o óleo de soja e, como fonte de volumoso, utilizou-se o feno de aveia (Avena sativa).

Diariamente, realizou-se a pesagem das rações fornecidas e das sobras e, três vezes por semana, efetuou-se a amostragem das rações fornecidas e das sobras. As amostras simples foram homogeneizadas, retirando-se as amostras compostas, que foram moídas em peneira de $1 \mathrm{~mm}$ e acondicionadas em frascos de polietileno para posteriores análises.

Para aferição do peso vivo, no início do experimento e a cada sete dias, foram realizadas as pesagens dos animais antes da alimentação da manhã, em jejum.

Semanalmente, foram realizadas coletas de sangue 4 horas após a alimentação da manhã, utilizando-se tubos de ensaio de $10 \mathrm{~mL}$, por meio de punção da veia jugular. $\mathrm{O}$ soro foi obtido por centrifugação a $3.500 \mathrm{rpm}$ por 15 minutos, sendo identificado, armazenado em minitubos ependorf e congelado. No soro foram analisados os níveis de colesterol, triglicerídeos e uréia, por meio do Analisador automático Merck Vitalab Selectra $2^{\circledR}$, no Laboratório de Bioquímica da UEM. 
Tabela 1 - Composição das rações experimentais (\%MS)

Table 1 - Ingredient composition of the experimental diets (\%DM)

\begin{tabular}{|c|c|c|c|c|c|}
\hline \multirow[t]{2}{*}{$\begin{array}{l}\text { Alimento } \\
\text { Feed }\end{array}$} & \multicolumn{5}{|c|}{$\begin{array}{c}\text { Nível de energia (Mcal de EM/kg MS) }{ }^{1} \\
\text { Energy level (Mcal of ME/kg DM) }\end{array}$} \\
\hline & 2,95 & 2,83 & 2,70 & 2,58 & 2,46 \\
\hline $\begin{array}{l}\text { Feno de aveia } \\
\text { Oat hay }\end{array}$ & 39,80 & 49,75 & 59,70 & 69,65 & 79,60 \\
\hline $\begin{array}{l}\text { Milho moído } \\
\text { Ground corn }\end{array}$ & 40,24 & 31,27 & 22,29 & 13,32 & 4,26 \\
\hline $\begin{array}{l}\text { Farelo de soja } \\
\text { Soybean meal }\end{array}$ & 13,93 & 13,67 & 13,42 & 13,16 & 13,00 \\
\hline $\begin{array}{l}\text { Óleo de soja } \\
\text { Soybean oil }\end{array}$ & 4,67 & 4,00 & 3,32 & 2,65 & 1,97 \\
\hline $\begin{array}{l}\text { Fosfato bicálcico } \\
\text { Dicalcium phosphate }\end{array}$ & 0,22 & 0,24 & 0,26 & 0,28 & 0,30 \\
\hline $\begin{array}{l}\text { Calcário } \\
\text { Limestone }\end{array}$ & 0,64 & 0,57 & 0,50 & 0,43 & 0,36 \\
\hline $\begin{array}{l}\text { Suplemento minera }{ }^{1} \\
\text { Mineral supplement }\end{array}$ & $\begin{array}{l}10,50 \\
{ }^{1}\end{array}$ & 0,50 & 0,50 & 0,50 & 0,50 \\
\hline $\begin{array}{l}\text { MS (\%) } \\
D M(\%)\end{array}$ & 90,48 & 90,40 & 91,65 & 91,72 & 92,44 \\
\hline $\begin{array}{l}\mathrm{PB}(\% \mathrm{MS}) \\
C P(\% D M)\end{array}$ & 15,05 & 15,27 & 15,29 & 15,26 & 15,03 \\
\hline $\begin{array}{l}\text { EE (\%MS) } \\
\text { FDN }(\% \mathrm{MS})\end{array}$ & $\begin{array}{r}6,81 \\
35,19\end{array}$ & $\begin{array}{r}5,81 \\
41,95\end{array}$ & $\begin{array}{r}5,01 \\
47,85\end{array}$ & $\begin{array}{r}3,71 \\
53,31\end{array}$ & $\begin{array}{r}3,00 \\
57,27\end{array}$ \\
\hline$N D F(\% D M)$ & & & & & \\
\hline $\begin{array}{l}\text { FDA }(\% \mathrm{MS}) \\
A D F(\% D M)\end{array}$ & 20,13 & 24,99 & 28,94 & 32,16 & 36,01 \\
\hline LIG (\%MS) & 3,99 & 5,10 & 5,89 & 6,26 & 6,67 \\
\hline CEL (\%MS) & 15,73 & 18,82 & 21,28 & 25,80 & 27,73 \\
\hline $\begin{array}{l}\text { CT }(\% \mathrm{MS})^{2} \\
\text { TC }(\% D M)\end{array}$ & 72,03 & 72,20 & 72,34 & 73,34 & 72,98 \\
\hline $\begin{array}{l}\text { CIN (\%MS) } \\
\text { Ash (\%DM) }\end{array}$ & 5,90 & 6,47 & 7,34 & 7,19 & 8,84 \\
\hline $\mathrm{Ca}(\% \mathrm{MS})^{3}$ & 0,45 & 0,45 & 0,45 & 0,45 & 0,45 \\
\hline $\mathrm{P}(\% \mathrm{MS})^{3}$ & 0,32 & 0,32 & 0,32 & 0,32 & 0,32 \\
\hline $\begin{array}{l}\mathrm{EM}(\mathrm{Mcal} / \mathrm{kg} \mathrm{MS})^{3} \\
M E(\text { Mcal } / \mathrm{kg} \mathrm{DM})\end{array}$ & 2,95 & 2,83 & 2,70 & 2,58 & 2,46 \\
\hline $\begin{array}{l}\text { NDT }(\% \mathrm{MS})^{3} \\
T D N\end{array}$ & 85,84 & 81,70 & 77,56 & 73,42 & 69,28 \\
\hline
\end{tabular}

1 Composição (Composition): 130 g Ca; 65 g P; 19 g Mg; 13 g S; 93 g Na; $145 \mathrm{~g} \mathrm{Cl} ; 10$ mg Se; 850 mg Cu; 700 mg Fe; 2.750 mg Zn; 1.000 mg Mn;

$120 \mathrm{mg} \mathrm{I} ; 70 \mathrm{mg} \mathrm{Co} ; 650 \mathrm{mg} \mathrm{F} ; 1.000 \mathrm{~g}$ de veículo (vehicle) q.s.p

2 Estimado pela fórmula de Sniffen et al. (1992): CT = $100-(\% \mathrm{~PB}+\% \mathrm{EE}$ $+\%$ Cinzas).

3 EM: energia metabolizável; dados tabulares obtidos do NRC (1996).

2 According to Sniffen et al. (1992): TC $=100-(\% C P+\% E E+\%$ Ash $)$

${ }^{3} \mathrm{ME}$ : metabolizable energy values according to the NRC (1996).

Para determinação da digestibilidade dos nutrientes, foram realizadas coletas de fezes, diretamente no reto dos animais, durante seis dias, às $8,10,12,14,16$ e $18 \mathrm{~h}$, respectivamente, de cada dia. Para as estimativas da excreção fecal, utilizou-se como indicador a FDN indigestível (FDNi), conforme proposto por Cochran et al. (1986). No entanto, a FDNi foi estimada pela incubação de amostras de alimento, sobras e fezes no rúmen, utilizando-se filtros F57 da Ankom ${ }^{\circledR}$, por 144 horas, seguida da análise de FDN, por meio das seguintes equações:

$$
\mathrm{EF}=\frac{\mathrm{CFDNi}}{\mathrm{FDNiF}}
$$

em que: $\mathrm{EF}=$ excreção fecal $(\mathrm{kg} / \mathrm{dia}) ; \mathrm{CFDN}_{\mathrm{i}}=$ consumo de $\mathrm{FDN}_{\mathrm{i}}(\mathrm{kg} /$ dia $) ; \mathrm{FDN}_{\mathrm{i}} \mathrm{F}=$ concentração de $\mathrm{FDN}_{\mathrm{i}}$ nas fezes $(\mathrm{kg} / \mathrm{kg})$;

$$
\mathrm{CFDNi}=\mathrm{FDNiA}-\mathrm{FDNiS}
$$

em que: $\mathrm{FDN}_{\mathrm{i}} \mathrm{A}=\mathrm{FDN}_{\mathrm{i}}$ presente no alimento oferecido ( $\mathrm{kg} / \mathrm{dia}) ; \mathrm{FDN}_{\mathrm{i}} \mathrm{S}=\mathrm{FDN}_{\mathrm{i}}$ presente nas sobras $(\mathrm{kg} / \mathrm{dia})$.

As amostras da ração fornecida, das sobras e das fezes foram analisadas quanto aos teores de MS, CIN, PB, EE, segundo metodologia descrita por Silva (1990), e FDN, segundo metodologia de Van Soest et al. (1991). As rações fornecidas foram analisadas também quanto aos teores de FDA, lignina e celulose. Para estimar os carboidratos totais, utilizou-se a fórmula descrita por Sniffen et al. (1992):

$$
\mathrm{CT}=100-(\% \mathrm{~PB}+\% \mathrm{EE}+\% \text { cinzas }) \text {. }
$$

$\mathrm{O}$ delineamento experimental utilizado foi o inteiramente casualizado, com quatro repetições por tratamento. Os dados foram analisados pelo programa SAEG (Sistema para Análises Estatísticas e Genéticas), desenvolvido pela Universidade Federal de Viçosa (UFV, 1997), conforme o seguinte modelo estatístico:

$$
\mathrm{Y}_{\mathrm{ij}}=\mu+\mathrm{b} 1(\mathrm{~N}-\mathrm{Nm})_{\mathrm{i}}+\mathrm{e}_{\mathrm{ij}}
$$

em que: $\mathrm{Y}_{\mathrm{ij}}$ : observação do animal j recebendo o nível de energia $i, i=2,95 ; 2,83 ; 2,70 ; 2,58$ e 2,$46 ; \mu$ : constante geral; b1: coeficiente linear de regressão da variável Y em função do nível de energia $\mathrm{i}, \mathrm{i}=2,95 ; 2,83 ; 2,70 ; 2,58$ e 2,$46 ; \mathrm{N}$ : efeito do nível de energia i, i $=2,95 ; 2,83 ; 2,70 ; 2,58$ e 2,$46 ; \mathrm{Nm}$ : média do nível de energia i, i $=2,95 ; 2,83 ; 2,70 ; 2,58$ e 2,46; $\mathrm{e}_{\mathrm{ij}}$ : erro aleatório associado a cada observação.

\section{Resultados e Discussão}

As médias observadas para peso vivo $(\mathrm{kg})$ e ingestões de MS ( $\mathrm{kg} / \mathrm{dia}, \% \mathrm{PV}$ e g/PV $\left.{ }^{0,75}\right)$, MO, PB, EE, CT, FDN e NDT ( $\mathrm{kg} / \mathrm{dia})$ durante o período pré-parto, encontram-se na Tabela 2 .

$\mathrm{O}$ fornecimento das dietas referentes aos tratamentos durante os 21 dias antecedentes ao parto não influenciou $(\mathrm{P}>0,05)$ o peso vivo $(\mathrm{kg})$ das cabras. Durante 21 dias préparto, não foram observadas diferenças $(\mathrm{P}>0,05)$ para as ingestões de $\mathrm{MS}$, em kg/dia, \%PV e g/PV ${ }^{0,75}, \mathrm{MO}, \mathrm{PB}, \mathrm{CT}$, FDN e NDT. A IMS neste período foi, em média, de 1,83\% PV. A baixa ingestão nesta fase pode ser atribuída à limitada capacidade de ingestão, pois é no terço final da gestação que ocorre o maior crescimento do feto, o que resulta em redução no volume do rúmen, em virtude da compressão do útero, podendo acarretar reduções, em vacas, de 25 a $35 \%$ do consumo (Drackley, 1999). No entanto, esta diferença no consumo entre as fases pré-parto e início de lactação pode atingir valores superiores para cabras leiteiras. 
Tabela 2 - Médias, equação de regressão, coeficientes de determinação $\left(R^{2}\right)$ e de variação (CV) para peso vivo (kg) e ingestões de MS (IMS), MO (IMO), PB (IPB), EE (IEE), CT (ICT), FDN (IFDN) e NDT (INDT) de acordo com os níveis de energia das rações para cabras Saanen no período pré-parto

Table 2 - Means, regression equation, $R$-square $\left(R^{2}\right)$ and coefficient of variation (CV) for body weight (kg), intakes of DM (DMI), OM (OMI), CP (CPI), EE (EEI), TC (TCI), NDF (NFDI), and TDN (TDNI) for prepartum Saanen goats fed diets with different energy levels

\begin{tabular}{|c|c|c|c|c|c|c|c|c|}
\hline & \multicolumn{5}{|c|}{$\begin{array}{c}\text { Nível de energia } \\
\text { Energy level }\end{array}$} & \multirow[t]{2}{*}{$\begin{array}{c}\text { Equação de regressão } \\
\text { Regression equation }\end{array}$} & \multirow[t]{2}{*}{$\mathrm{R}^{2}$} & \multirow[t]{2}{*}{$\mathrm{CV}$} \\
\hline & 2,95 & 2,83 & 2,70 & 2,58 & 2,46 & & & \\
\hline Peso vivo (kg) & 67,53 & 71,91 & 72,04 & 70,63 & 70,85 & $\hat{\mathrm{Y}}=70,65$ & $\mathrm{NS}^{1}$ & 10,46 \\
\hline $\begin{array}{l}\text { Body weight }(\mathrm{kg}) \\
\text { IMS }(\mathrm{kg} / \mathrm{dia})\end{array}$ & 1,19 & 1,08 & 0,90 & 1,14 & 1,21 & $\hat{\mathrm{Y}}=1,10$ & NS & 34,49 \\
\hline $\begin{array}{l}\text { IMS }(\% \mathrm{PV}) \\
D M I(\% B W)\end{array}$ & 2,00 & 1,86 & 1,87 & 1,62 & 1,86 & $\hat{\mathrm{Y}}=1,83$ & NS & 20,88 \\
\hline $\begin{array}{l}\text { IMS }\left(\mathrm{g} / \mathrm{PV}^{0,75}\right) \\
D M I\left(g / B W^{0.75}\right)\end{array}$ & 46,09 & 42,51 & 39,25 & 42,02 & 45,66 & $\hat{\mathrm{Y}}=43,03$ & NS & 19,74 \\
\hline $\begin{array}{l}\text { IMO (kg/dia) } \\
\text { OMI (kg/day) }\end{array}$ & 1,24 & 1,11 & 0,91 & 1,15 & 1,19 & $\hat{\mathrm{Y}}=1,12$ & NS & 34,64 \\
\hline $\begin{array}{l}\text { IPB (kg/dia) } \\
\text { CPI (kg/day) }\end{array}$ & 0,20 & 0,18 & 0,15 & 0,19 & 0,20 & $\hat{\mathrm{Y}}=0,19$ & NS & 34,36 \\
\hline $\begin{array}{l}\text { IEE ( } \mathrm{kg} / \mathrm{dia}) \\
\text { EEI ( } \mathrm{kg} / \text { day })\end{array}$ & 0,11 & 0,08 & 0,05 & 0,05 & 0,03 & $\hat{\mathrm{Y}}=-0,31+0,137 \mathrm{X}$ & 0,52 & 36,92 \\
\hline $\begin{array}{l}\text { ICT ( } \mathrm{kg} / \mathrm{dia}) \\
\text { TCI }(\mathrm{kg} / \text { day })\end{array}$ & 0,93 & 0,86 & 0,70 & 0,90 & 0,95 & $\hat{\mathrm{Y}}=0,87$ & NS & 34,64 \\
\hline $\begin{array}{l}\text { IFDN (kg/dia) } \\
N D F I \text { (kg/day) }\end{array}$ & 0,59 & 0,50 & 0,48 & 0,72 & 0,76 & $\hat{\mathrm{Y}}=0,61$ & NS & 36,18 \\
\hline $\begin{array}{l}\text { INDT (kg/day) } \\
\text { TDNI (kg/day) }\end{array}$ & 1,02 & 0,88 & 0,70 & 0,83 & 0,84 & $\hat{\mathrm{Y}}=0,85$ & NS & 34,85 \\
\hline
\end{tabular}

${ }^{1} \mathrm{NS}=\mathrm{P}>0,05$ (NS: Not significant, $P>0.05$ ).

Zambom et al. (2005) observaram redução de 67,45\% na ingestão de MS em relação à fase inicial de lactação.

Quanto à ingestão de extrato etéreo (IEE), observou-se efeito linear positivo $(\mathrm{P}=0,0002)$ com o aumento do nível energético da ração. Rodrigues et al. (2001), em experimento com cabras gestantes da raça Alpina, testaram três níveis de energia na dieta $(1,62 ; 2,21$ e 2,78 Mcal EM/kg MS) e verificaram que as cabras que receberam a ração com menor nível energético apresentaram menor IMS, no entanto, não foram verificadas diferenças $(P>0,05)$ entre as demais dietas. A IMS para as dietas com 2,21 e $2,78 \mathrm{Mcal} \mathrm{EM} / \mathrm{kg} \mathrm{MS}$ foi de $1,72 \% \mathrm{PV}$, semelhante à observada neste estudo $(1,83 \% \mathrm{PV})$.

Goetsch et al. (2001) avaliaram relações volumoso:concentrado para cabras Alpinas $(65,88 \mathrm{~kg}$ de $\mathrm{PV})$ em diferentes fases fisiológicas. Durante o período préparto, os tratamentos foram 35:65, 50:50 e 65:35, com níveis energéticos correspondentes de 2,65;2,42 e 2,18 Mcal $\mathrm{EM} / \mathrm{kg}$ MS. Os autores não obtiveram diferenças $(\mathrm{P}>0,05)$ para ingestão de MS (kg/dia) entre os tratamentos avaliados e encontraram média de 2,15 kg de MS/dia. Sahlu et al. (1995), trabalhando com cabras Alpinas $(67,50 \mathrm{~kg})$ em final de gestação utilizando dietas com $14,5 \%$ de $\mathrm{PB}$ e três níveis de $\operatorname{EM}(1,80 ; 2,16$ e $2,53 \mathrm{Mcal} / \mathrm{kg}$ de MS), não verificaram diferenças na ingestão de MS $(2,18 \mathrm{~kg})$.
Conforme descrito na Tabela 3, observou-se efeito linear positivo $(\mathrm{P}<0,05)$ do aumento de energia na ração sobre os coeficientes de digestibilidade (DMS, DMO, DEE, DCT, DFDN e DEB) dos nutrientes. As rações com menor nível energético apresentaram maior proporção de volumoso, o que elevou o teor de fibra, resultando em menor digestibilidade da MS e, conseqüentemente, dos nutrientes. Não houve efeito $(\mathrm{P}>0,05)$ do nível energético sobre a digestibilidade da $\mathrm{PB}$, pois as rações apresentaram em média o mesmo teor de PB $(15,2 \%)$.

As concentrações de colesterol e uréia no sangue (Tabela 4) não foram influenciadas $(\mathrm{P}>0,05)$ pelo nível de energia da ração. Todavia, verificou-se efeito linear positivo ( $\mathrm{P}=0,046)$ do nível energético das rações sobre os valores de EE, que foram maiores nas cabras alimentadas com as rações mais energéticas. Porém, provavelmente os elevados valores obtidos para triglicerídeos não alteraram o equilíbrio nutricional dos animais, pois os demais parâmetros sangüíneos estavam próximos às concentrações indicadas para animais em pré-parto: 14,97 a 41,92 mg/dL para uréia e até $150 \mathrm{mg} / \mathrm{dL}$ para colesterol (Wittwer, 2000a).

Sahlu et al. (1995), trabalhando com cabras Alpinas $(67,50 \mathrm{~kg})$ em final de gestação alimentadas com dietas com $14,5 \%$ de PB e três níveis de EM $(1,80 ; 2,16$ e $2,53 \mathrm{Mcal} / \mathrm{kg}$ de MS), não verificaram diferenças $(\mathrm{P}>0,05)$ na concentra- 
Tabela 3 - Médias, equação de regressão e coeficientes de determinação $\left(R^{2}\right)$ e variação (CV) para as digestibilidades de $M S$ (DMS), $\mathrm{MO}$ (DMO), PB (DPB), EE (DEE), CT (DCT), FDN (DFDN) e EB (DEB), em função dos níveis de energia em rações para cabras Saanen no período pré-parto

Table 3 - Means, regression equation, $R$-square $\left(R^{2}\right)$ and coefficient of variation (CV) for digestibilities of $D M(D M D), O M(O M D), C P(C P D), E E(E E D)$, $T C$ (TCD), NDF (NDFD), and GE (GED) for prepartum Saanen goats fed diets with different energy leve/s

\begin{tabular}{|c|c|c|c|c|c|c|c|c|}
\hline & \multicolumn{5}{|c|}{$\begin{array}{l}\text { Nível de energia } \\
\text { Energy level }\end{array}$} & \multirow[t]{2}{*}{$\begin{array}{c}\text { Equação de regressão } \\
\text { Regression equation }\end{array}$} & \multirow[t]{2}{*}{$\mathrm{R}^{2}$} & \multirow[t]{2}{*}{$\mathrm{CV}$} \\
\hline & 2,95 & 2,83 & 2,70 & 2,58 & 2,46 & & & \\
\hline DMS (DMD) (\%) & 59,15 & 53,74 & 50,20 & 47,09 & 43,18 & $\hat{\mathrm{Y}}=-33,553+31,133 \mathrm{X}$ & 0,61 & 8,50 \\
\hline $\mathrm{DMO}(O M D)(\%)$ & 61,42 & 55,57 & 52,03 & 49,00 & 44,10 & $\hat{\mathrm{Y}}=-37,196+33,133 \mathrm{X}$ & 0,65 & 8,03 \\
\hline $\mathrm{DPB}(C P D)(\%)$ & 63,09 & 65,80 & 59,93 & 62,98 & 65,17 & $\hat{\mathrm{Y}}=63,40$ & NS & 6,99 \\
\hline $\operatorname{DEE}(E E D)(\%)$ & 89,31 & 87,68 & 83,18 & 80,42 & 70,09 & $\hat{\mathrm{Y}}=-16,832+36,680 \mathrm{X}$ & 0,80 & 3,84 \\
\hline $\mathrm{DCT}(T C D)(\%)$ & 52,90 & 57,75 & 45,24 & 40,41 & 41,88 & $\hat{\mathrm{Y}}=-44,474+34,074 \mathrm{X}$ & 0,52 & 11,89 \\
\hline DFDN (NDFD) (\%) & 52,94 & 57,57 & 45,30 & 40,71 & 42,68 & $\hat{\mathrm{Y}}=-39,940+32,466 \mathrm{X}$ & 0,50 & 11,88 \\
\hline $\mathrm{DEB}(G E D)(\%)$ & 55,35 & 57,98 & 45,68 & 42,16 & 42,83 & $\hat{\mathrm{Y}}=-45,678+34,932 \mathrm{X}$ & 0,54 & 11,43 \\
\hline
\end{tabular}

${ }^{1} \mathrm{NS}=\mathrm{P}>0,05$ (NS: Not significant, $\left.P>0.05\right)$.

Tabela 4 - Médias, equação de regressão e coeficientes de determinação $\left(R^{2}\right)$ e variação $(C V)$ dos parâmetros sangüíneos (colesterol, triglicerídeos e uréia; $\mathrm{mg} / \mathrm{dL}$ ) no soro de cabras Saanen no período pré-parto alimentadas com rações com diferentes níveis de energia

Table 4 - Means, regression equation, $R$-square $\left(R^{2}\right)$ and coefficient of variation (CV) of blood parameters (cholesterol, triglycerides and urea, $\mathrm{mg} / \mathrm{dL}$ ) for prepartum Saanen goats fed diets with different energy levels

\begin{tabular}{|c|c|c|c|c|c|c|c|c|}
\hline & \multicolumn{5}{|c|}{$\begin{array}{c}\text { Nível de energia } \\
\text { Energy level }\end{array}$} & \multirow[t]{2}{*}{$\begin{array}{c}\text { Equação de regressão } \\
\text { Regression equation }\end{array}$} & \multirow[t]{2}{*}{$\mathrm{R}^{2}$} & \multirow[t]{2}{*}{$\mathrm{CV}$} \\
\hline & 2,95 & 2,83 & 2,70 & 2,58 & 2,46 & & & \\
\hline \multicolumn{9}{|l|}{ Cholesterol $(\mathrm{mg} / \mathrm{dL})$} \\
\hline Triglicerídeos $(\mathrm{mg} / \mathrm{dL})$ & 39,63 & 31,75 & 32,13 & 29,97 & 24,21 & $\hat{\mathrm{Y}}=-39,083+26,089 \mathrm{X}$ & 0,87 & 30,71 \\
\hline \multicolumn{9}{|l|}{ Triglycerides $(\mathrm{mg} / \mathrm{dL})$} \\
\hline Urea $(\mathrm{mg} / \mathrm{dL})$ & & & & & & & & \\
\hline
\end{tabular}

${ }^{1} \mathrm{NS}=\mathrm{P}>0,05$ (NS: Not significant, $P>0.05$ ).

ção de uréia no sangue $(11,67 \mathrm{mg} / \mathrm{dL})$, que apresentou valores inferiores aos obtidos neste estudo. Provavelmente, estas diferenças estão relacionadas a erros metodológicos, pois os valores obtidos por Sahlu et al. (1995) podem ser de nitrogênio uréico no sangue, o que corresponderia a aproximadamente $25,93 \mathrm{mg} / \mathrm{dL}$ de uréia no sangue.

A relação entre os níveis de proteína e energia nas rações experimentais foi adequada, pois não foi observado efeito dos níveis energéticos na concentração de uréia plasmática, sendo que a concentração de uréia sangüínea está intimamente correlacionada ao teor de proteína na dieta, ao aporte energético da ração e à interação entre esses fatores.

Beynen et al. (2000) estudaram a influência do teor de gordura na dieta - ração com amido de milho nativo, óleo de oliva ou óleo de palma contendo 2,$6 ; 8,4$ ou $8,8 \%$ de EE, respectivamente-e no plasma por meio das concentrações de colesterol e triglicerídeos em cabras Dutch White nãogestantes e não-lactantes $(58,8 \mathrm{~kg})$. Esses autores verifica- ram que a utilização de altos níveis de óleo na dieta, média de $8,6 \%$, elevou os níveis de colesterol $(156,89 \mathrm{mg} / \mathrm{dL})$ e triglicerídeos $(16,77 \mathrm{mg} / \mathrm{dL})$ no plasma, em comparação a uma ração sem adição de óleo $(82,04 \mathrm{mg} / \mathrm{dL}$ para colesterol e $11,38 \mathrm{mg} / \mathrm{dL}$ para triglicerídeos).

Considerando os resultados observados para as concentrações de colesterol, triglicerídeos e uréia no plasma, pode-se afirmar que a energia fornecida neste estudo foi suficiente para suprir as exigências de mantença e gestação, não incidindo desordens metabólicas nos animais.

\section{Conclusões}

Os diferentes níveis de energia utilizados não modificaram a ingestão de matéria seca e nutrientes e os parâmetros sangüíneos de cabras Saanen durante o préparto. Entretanto, o maior nível de energia possibilitou, por meio da digestibilidade, melhor aporte de nutrientes para os animais. 


\section{Literatura Citada}

AGRICULTURAL AND FOOD RESEARCH COUNCIL - AFRC. Energy and protein requirements of ruminant. Wallingford: Cab International, 1993. 159p.

ARRUDA, F.A.V.; BARROS, N.N.; SILVA, F.L.R. Efeito da suplementação no terço final da gestação sobre a produção de leite, em cabras mestiças. In: REUNIÃO ANUAL DA SOCIEDADE BRASILEIRA DE ZOOTECNIA, 33., 1996, Fortaleza. Anais... Fortaleza: Sociedade Brasileira de Zootecnia, 1996, p.257-259.

BEYNEN, A.C.; SCHONEWILLE, J.T.; TERPSTRA, A.H.M. Influence of amount and type of dietary fat on plasma cholesterol concentrations in goats. Small Ruminant Research, v.35, n.2, p.141-147, 2000.

COCHRAN, R.C., ADAMS, D.C., WALLACE, J.D. et al. Predicting digestibility of different diets with internal markers: evaluation of four potential markers. Journal of Animal Science, v.63, n.5, p.1476-1483, 1986.

CONTRERAS, P.A.;WITTWER, F.; BÖHMWALD, H. Uso dos perfis metabólicos no monitoramento nutricional dos ovinos. In: GONZÁLEZ, F.H.D.; BARCELLOS, J.O.; OSPINA, H. et al. (Ed.) Perfil metabólico em ruminantes: seu uso em nutrição e doenças nutricionais. Porto Alegre: Universidade Federal do Rio Grande do Sul, 2000. p.75-88.

DRACKLEY, J.K. Biology of dairy cows during the transition period: the final frontier. Journal of Dairy Science, v.82, n.11, p.2259-2273, 1999 .

GOETSCH, A.L.; DETWEILER, G.; SAHLU, T. et al. Dairy goat performance with different dietary concentrate levels in late lactation. Small Ruminant Research, v.41, n.2, p.117-125, 2001 .

HEAD, H.H.; GULAY, M.S. Recentes avanços na nutrição de vacas no período de transição. In: SINLEITE, 2., 2001, Lavras. Anais... Lavras: Universidade Federal de Lavras, 2001, p.121-137.

NATIONAL RESEARCH COUNCIL - NRC. Nutrient requirements of goats. Washington, D.C.: National Academy of Sciences, 1981. $91 \mathrm{p}$.

NATIONAL RESEARCH COUNCIL - NRC. Nutrient requirements of beef cattle. Washington, D.C.: National Academy of Sciences, 1996. 242p.

NATIONAL RESEARCH COUNCIL - NRC. Nutrient requirements of dairy cattle. 7.rev.ed. Washington, D.C.: National Academy of Sciences, 2001. 254p.
RODRIGUES, C.F.; RODRIGUES, M.T.; BRANCO, R.H. et al. Influência do nível energético da dieta sobre o consumo de cabras alpinas durante o pré-parto. In: REUNIÃO ANUAL DA SOCIEDADE BRASILEIRA DE ZOOTECNIA, 38., 2001, Piracicaba. Anais... Piracibaca: Sociedade Brasileira de Zootecnia, 2001. p.1391-1392.

SAHLU, T.; HART, S.P.; LE-TRONG, T. et al. Influence of prepartum protein and energy concentrations for dairy goats during pregnancy and early lactation. Journal of Dairy Science, v.78, n.2, p.378-387, 1995.

SILVA, D.J. Análise de alimentos: métodos químicos e biológicos. Viçosa, MG: Universidade Federal de Viçosa, 1990. 166p.

SNIFFEN, C.J.; O'CONNOR, J.D.; Van SOEST, P.J. et al. A net carbohydrate and protein system for evaluating cattle diets: II. Carbohydrate and protein availability. Journal of Animal Science, v.70, n.10, p.3562-3577, 1992.

UNIVERSIDADE FEDERAL DE VIÇOSA - UFV. SAEG - Sistema para análises estatísticas e genéticas. Versão 7.1. Viçosa, MG: 1997. 150p (Manual do usuário).

Van SOEST, P.J.; ROBERTSON, J.B.; LEWIS, B.A. Symposium: carbohydrate metodology, metabolism, and nutritional implications in dairy cattle. Journal of Dairy Science, v.74, n. 10, p.3583-3597, 1991 .

WITTWER, F. Diagnóstico dos desequilíbrios metabólicos de energia em rebanhos bovinos. In: GONZÁLEZ, F.H.D.; BARCELLOS, J.O.; OSPINA, H. et al. (Eds.) Perfil metabólico em ruminantes: seu uso em nutrição e doenças nutricionais. Porto Alegre: Universidade Federal do Rio Grande do Sul, 2000a. p.9-22.

WITTWER, F. Marcadores bioquímicos no controle de problemas metabólicos nutricionais em gado de leite. In: GONZÁLEZ, F.H.D., BARCEllos, J.O., OSPINA, H. et al. (Eds.) Perfil metabólico em ruminantes: seu uso em nutrição e doenças nutricionais. Porto Alegre: Universidade Federal do Rio Grande do Sul, 2000b. p.53-62.

ZAMBOM, M.A.; ALCALDE, C.R.; SILVA, K.T. et al. Ingestão, digestibilidade das rações e produção de leite em cabras saanen submetidas a diferentes relações volumoso:concentrado na ração. Revista Brasileira de Zootecnia, v.34, n.6, p.25052514, 2005 (supl.). 